\title{
Neck synovial sarcoma: case presentation
}

\author{
KONSTANTINOS SAPALIDIS ${ }^{1)}$, StILIANI LASKOU ${ }^{1)}$, VASILIKI MANAKI ${ }^{1)}$, VASILIKI MAGRA ${ }^{1)}$, STELIAN PANTEA ${ }^{2),}$

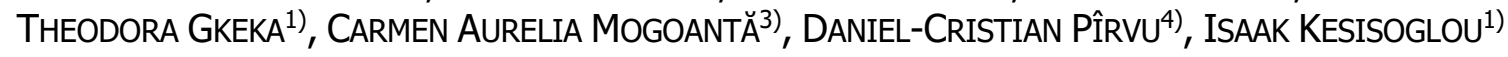

\author{
1) $3^{\text {rd }}$ Department of Surgery, AHEPA University Hospital, Medical School, Aristotle University of Thessaloniki, \\ Greece \\ 2) Department of Surgery, Victor Babeş University of Medicine and Pharmacy, Timişoara, Romania \\ 3) Department of ENT, Faculty of Medicine, University of Medicine and Pharmacy of Craiova, Romania \\ 4) Department of Internal Medicine, Faculty of Medicine, University of Medicine and Pharmacy of Craiova, \\ Romania
}

\begin{abstract}
Head and neck synovial sarcoma (HNSS) is a rare tumor with a few case reports or case series being published in the literature. We present the case of a 68-year-old patient admitted to our department for management of a palpable neck mass. After initial investigation and due to major problems of differential diagnosis, there was performed a wide excision of the tumor. Histopathology examination revealed an HNSS.
\end{abstract}

Keywords: synovial sarcoma, neck, SYT-SSX1 fusion gene, treatment.

\section{ㅁ Introduction}

Synovial sarcomas (SS) are soft tissue tumors derived from pluripotent mesenchymal cells that bear a similar microscopic resemblance to synovial cells [1]. They constitute about $10 \%$ of all sarcomas [2], being mainly discovered in the deep soft tissues of lower extremities, such as the knee and ankle. SS can rarely be detected in the head and neck region (HNSS - head and neck synovial sarcoma) [3]. HNSS possess a diagnostic challenge since the head and neck region is a site of multiple tumors. Moreover, little characteristic radiological features may be depicted on both computed tomography (CT) and magnetic resonance imaging (MRI) examination [4, 5]. A clear diagnosis must be histopathologically established. Due to the rarity of HNSS and lack of international treatment guidelines, its management also poses a challenge $[1,4$ 6]. Clear margins surgical resection represents the first step of the treatment [4]. Adjuvant therapy may also be applied, depending on each individual case.

\section{Aim}

The present paper reports a new case of neck SS, emphasizing on the imaging examination and treatment options.

\section{Case presentation}

A 68-year-old female visited our Outpatient Department two years post-thyroidectomy. She had noticed the presence of a right-sided mildly tender mass for two months. On examination, it was situated in the level II region of the neck. The mass was firm, smooth and regular. It was not fluctuant or pulsatile and was tethered to underlying tissues.
The lesion was initially thought to be a locoregional recurrence of thyroid cancer. However, on review of her medical record no evidence of thyroid malignancy was histologically observed. Ultrasonography (US) revealed a $3.98 / 2.21 \mathrm{~cm}$ irregular hypoechoic mass behind the right submandibular area without pathological neck lymphadenopathy (Figure 1), while CT showed a homogenous, well-defined mass up to $2.2 / 2.9 / 4.1 \mathrm{~cm}$ in right level II region (Figure 2).

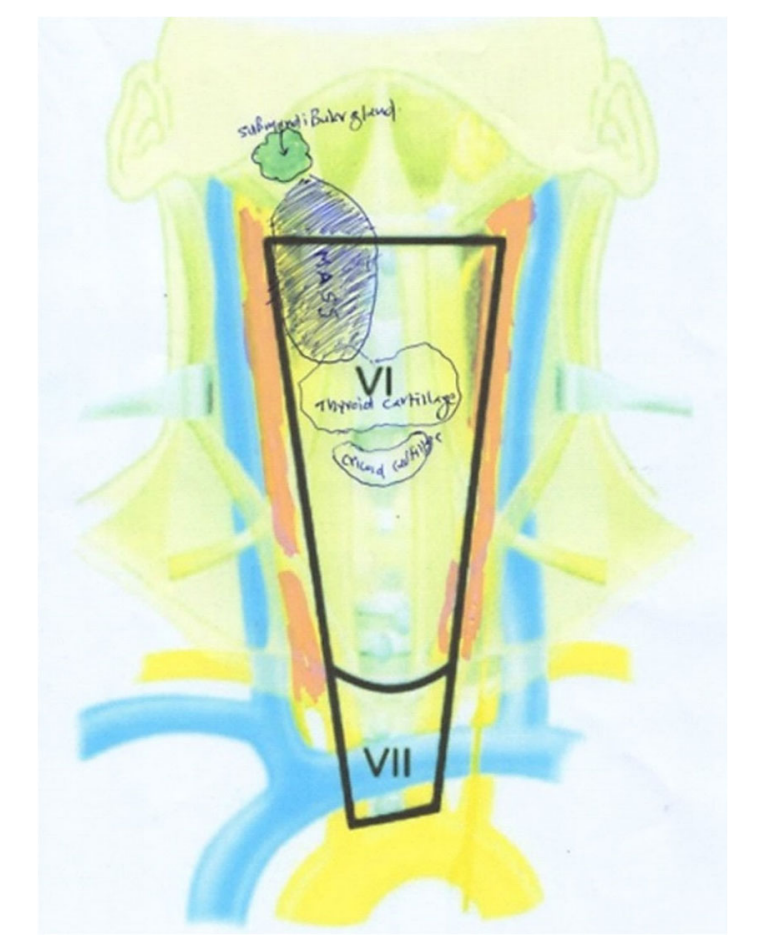

Figure 1 - Preoperative cervical mapping picture.

This is an open-access article distributed under the terms of a Creative Commons Attribution-NonCommercial-ShareAlike 4.0 International Public License, which permits unrestricted use, adaptation, distribution and reproduction in any medium, non-commercially, provided the new creations are licensed under identical terms as the original work and the original work is properly cited. 


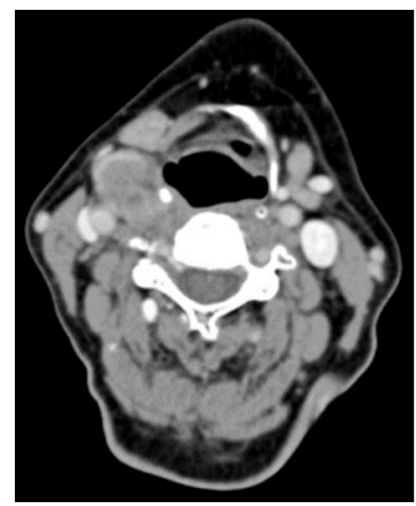

Figure 2-CT image depicting the lesion in right level II area. CT: Computed tomography.

Paraclinical investigations were within normal limits, while lung radiography showed no pathological changes.

Since definite diagnosis was not feasible, wide local excision was performed (Figure 3, a and b). Macroscopically, the tumor was a well-defined, nearly round, elastic, with a white nodule of $3.7 \mathrm{~cm}$ in its largest diameter (Figure 4).

Microscopic examination showed that the tumor was bounded by a thick connective capsule of collagen fibers with a concentric disposition, and fibroblast-type connective cells (Figure 5a). The tumor cells were arranged in bundles, with hardly visible intercellular boundaries, large, oval, and weakly colored nuclei, with delicate chromatin, without apparent presence of nucleoli, and poor, acidophilic cytoplasm (Figure 5b). Tumor cells showed moderate cellular and nuclear atypia and a reduced number of mitoses. Rare areas of tumor necrosis were observed (Figure 5c).
Examination with strong microscopic lenses revealed the existence of a network of small blood vessels (arterioles, capillaries, venules) with thin walls, microscopic appearance similar to a hemagiopericytoma (Figure 5d).

To establish a more precise positive and differential diagnosis, the pathologists decided to perform an immunohistochemical (IHC) study in which the following markers were used: anti-vimentin, anti-cluster of differentiation (CD) 99, anti-CD56, anti-CD34, anti-cytokeratin (CK) AE1/AE3, anti-epithelial membrane antigen (EMA), anti-S100, antidesmin and anti-alpha-smooth muscle actin ( $\alpha$-SMA). IHC staining showed that the neoplastic cells were intensely positive for vimentin and CD56 (Figure 6, a and b), moderately positive for CD99 and EMA (Figure 6, c and d), and intensely positive for CK AE1/AE3 (Figure 6e).

Tumor cells were negative for S100 (Figure 6f), desmin (Figure 6g), $\alpha$-SMA (Figure 6h), and CD34. In contrast, CD34 immunolabeling showed the presence of intense vascularization in the tumor (Figure 6i).

Performing the real-time polymerase chain reaction (RT-PCR) showed that in the genome of tumor cells there is a fusion of synaptotagmin $(S Y T)$-SSX family member 1 (SSX1) genes (Figure 7, a and b).

Clinical, pathological and IHC findings indicated that the tumor was a typical encapsulated monophasic SS.

Due to the aggressive nature of the neoplasm, a positronemission tomography (PET)/CT scan was recommended, revealing no hypermetabolic masses though (Figure 8, a and b). Currently, the patient is under oncological surveillance.

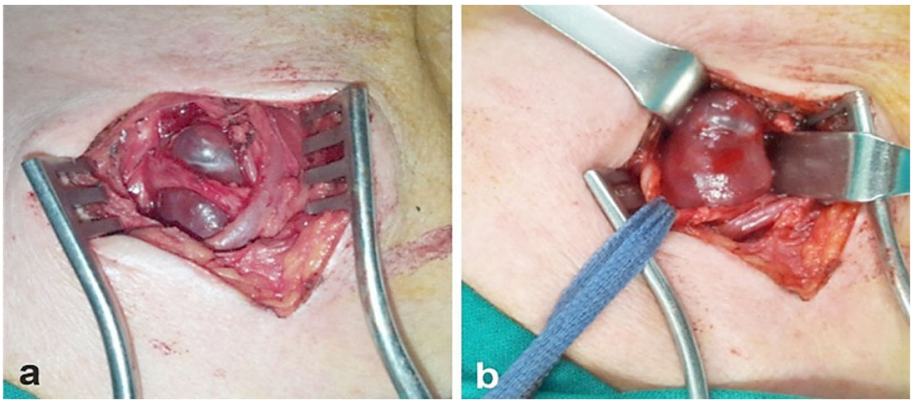

Figure 3 - (a and b) SS dissection. The blue tape holds the internal carotid artery. SS: Synovial sarcoma.

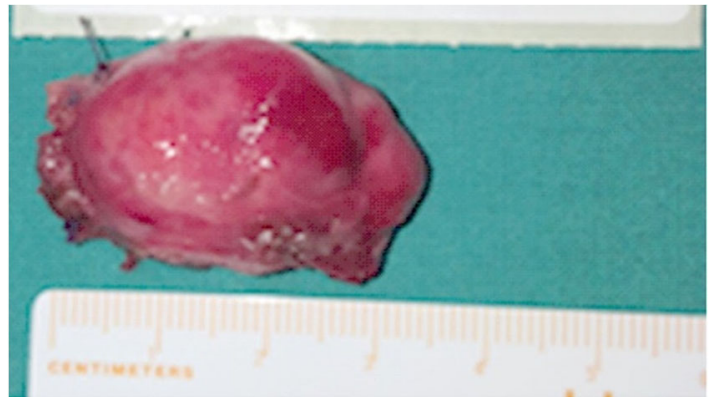

Figure 4-Macroscopic image of the SS: nodular tumor, encapsulated, well delimited, about $3.7 \mathrm{~cm}$ in diameter. SS: Synovial sarcoma.
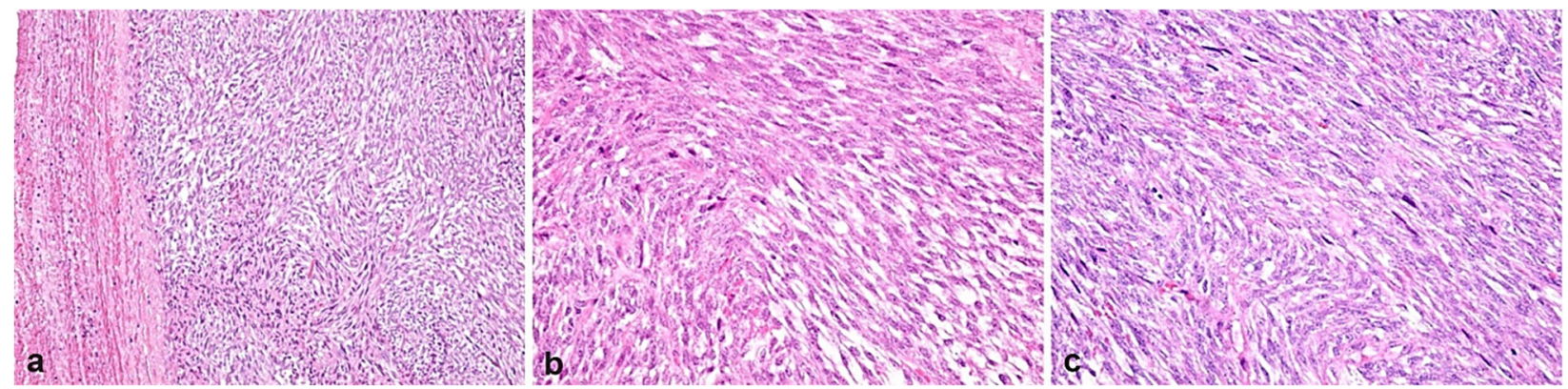

Figure 5-(a) The tumor surrounded by fibrous capsule; (b) The tumor cells are spindle with mild nuclear atypia; (c) Spindle tumor cells with mild nuclear atypia and indistinct cellular borders; (d) Focal hemangiopericytomatous pattern. HE staining: (a and d) $\times 100$; (b and c) $\times 200$. HE: Hematoxylin-Eosin.

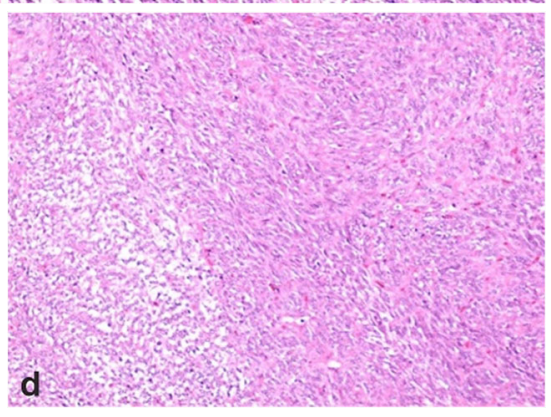



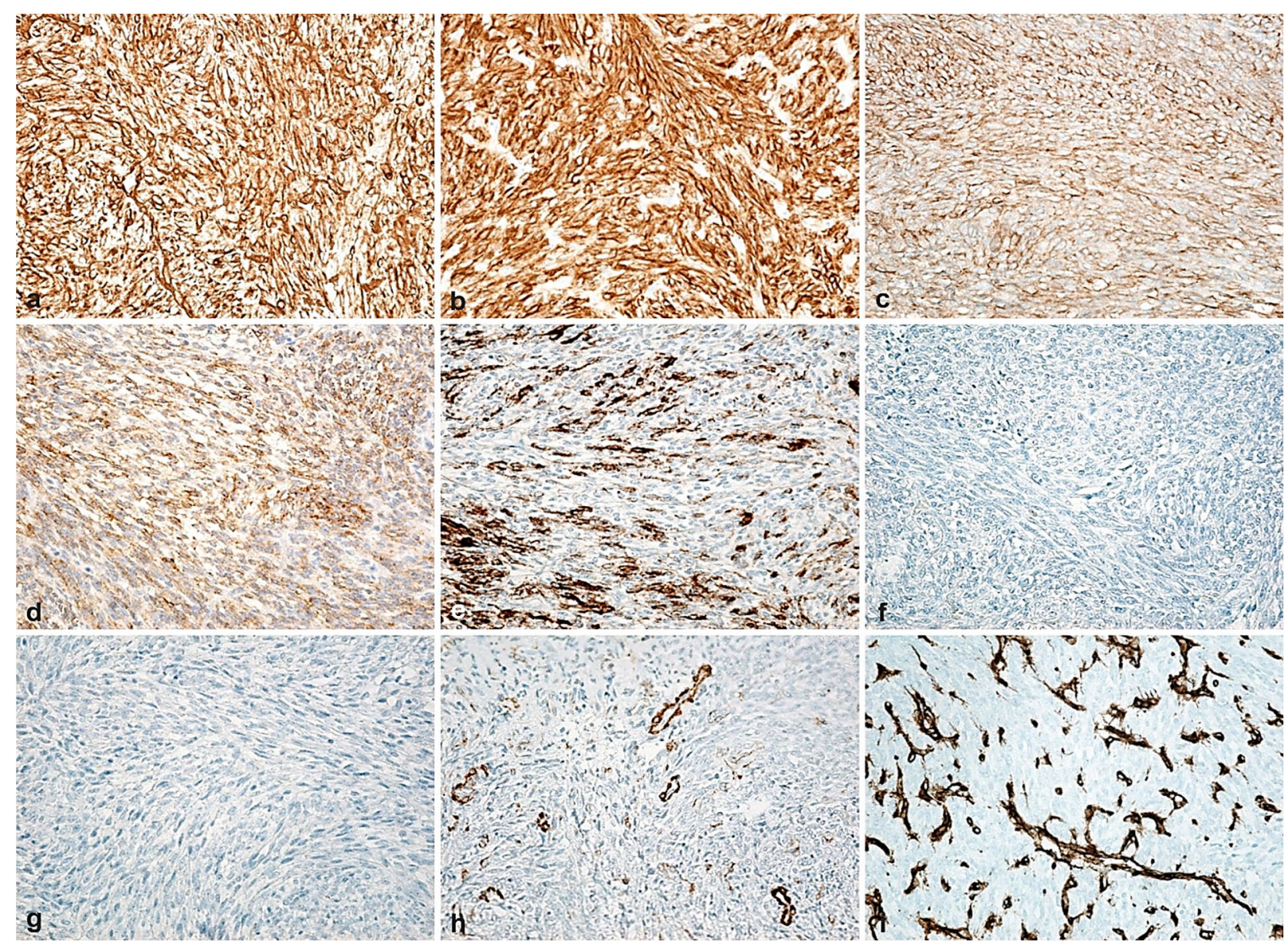

Figure 6 - (a) The tumor cells are positive for vimentin; (b) The tumor cells are positive for CD56; (c) The tumor cells are positive for CD99; (d) Tumor cells with a moderately positive immunoreaction to EMA; (e) Several tumor cells are positive for CK AE1/AE3; (f) Negative immunoreaction of tumor cells to S100 protein; (g) Negative immunoreaction of tumor cells to desmin; (h) Negative immunoreaction of tumor cells to $\alpha-S M A$, except for muscle cells in the blood vessels' wall; (i) Negative immunoreaction of tumor cells to CD34, except for endothelial cells in the blood vessels' wall. Immunolabeling with anti-vimentin antibody: (a) $\times 200$. Immunolabeling with anti-CD56 antibody: (b) $\times 200$. Immunolabeling with anti-CD99 antibody: (c) $\times 200$. Immunolabeling with anti-EMA antibody: (d) $\times 200$. Immunolabeling with anti-CK AE1/AE3 antibody: $(e) \times 200$. Immunolabeling with anti-S100 antibody: $(f) \times 200$. Immunolabeling with anti-desmin antibody: $(g) \times 200$. Immunolabeling with anti- $\alpha-S M A$ antibody: $(h) \times 200$. Immunolabeling with anti-CD34 antibody: (i) $\times 200$. a-SMA: Alpha-smooth muscle actin; CD: Cluster of differentiation; CK: Cytokeratin; EMA: Epithelial membrane antigen.
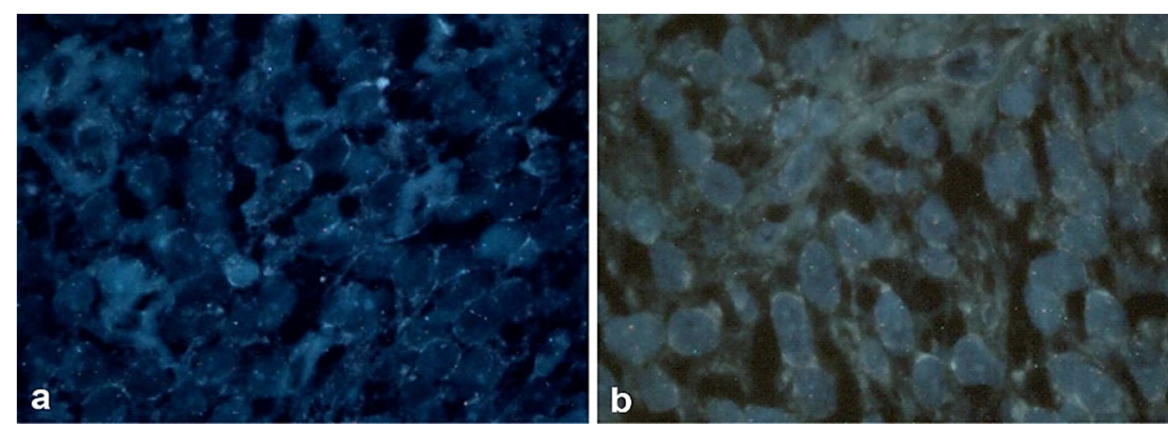

Figure 7 - (a and b) Presence of break apart and rearrangement of SSX1/4 genes. SSX: SSX family member $1 / 4$.

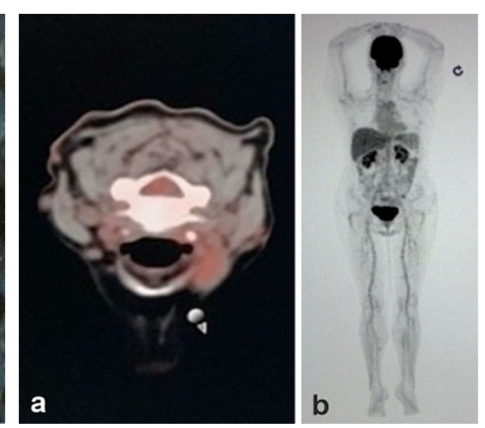

Figure 8 - PET/CT examination shows no hypermetabolic masses:

(a) Cross section at the neck;

(b) Longitudinal section of the body. PET/CT: Positron emission tomography/computed tomography.

\section{ㅁ Discussions}

SS are scarce soft tissue malignancies more often seen in males with a 3:2 ratio compared to females $[3,5]$.
Age at presentation varies between the $3^{\text {rd }}$ and $5^{\text {th }}$ decade of life. Such tumors are frequently present in lower extremities. Only $3 \%$ of SS appear in the area of head and neck with the most usual site being the hypopharynx and 
larynx the least frequent location [1, 7]. Gopalakrishnan et al. report that patients may have primary tumors at several sites in the head and neck. SS are considered to originate from pluripotent mesenchymal cells that can differentiate into epithelial and mesenchymal lineages [1, 7]. However, as observed with synovial cell sarcomas (SCS) occurring in parapharyngeal, hypopharyngeal or laryngeal regions, SCS can arise from cells outside the synovium. An asymptomatic lesion may be the first manifestation of the disease. When symptomatic, the clinical presentation is atypical and depends on location. Dysphagia, dyspnea, dysphonia, discomfort, and a palpable mass are the most commonly reported symptoms $[4,7,8]$.

$\mathrm{CT}$ and MRI examinations may help in diagnosis. CT examination typically shows a multi localized tumor with smooth margins and heterogeneous enhancement after injection of contrast agent. Tumors may contain calcifications. MRI examination reveals a lesion of intermediate intensity on T1-weighted sequences and of variable intensity on T2weighted sequences, with heterogeneous enhancement after injection of contrast substance. Ouansafi et al. also propose fine-needle aspiration (FNA) biopsy for diagnosing this kind of sarcoma [9]. In the head and neck region, the parapharyngeal space is the place most frequently involved in the appearance of SS $[10,11]$. These findings, however, may be similar to other head and neck tumors, either benign or malignant [12-14]. Benign lesions include inflammatory lymphadenopathy, branchial, dermoid, and thyroglossal duct cysts, and also benign mesenchymal tumors, such as schwannoma, neurofibroma, lipoma, or even tumors of ectopic minor salivary glands. Malignancies such as squamous cell carcinoma, sarcomas of the head and neck like rhabdomyosarcomas, leiomyosarcomas, fibrosarcomas, and liposarcomas and non-Hodgkin's lymphoma could be also found.

The SS treatment of choice is clear margins surgical resection $[1,8]$. Prophylactic neck dissection is not known to have a benefit for the survival rate since SS rarely shows lymphatic spread. Chemotherapy as adjuvant or neoadjuvant treatment remains controversial [8], being performed in patients with high risk of metastatic disease [6]. Adjuvant radiotherapy can be applied in the presence of risk factors, especially for tumors over $5 \mathrm{~cm}$ in diameter $[11,15]$. SS, although characterized by its slow development, has poor prognosis due to local recurrences and distant metastases, particularly in the lungs $[8,16]$. Follow-up should be of lifelong duration. For metastatic disease, palliation seems to be justified.

No distinctive features are found on gross appearance for SCS. Tumors may have an ivory gray-white appearance and an oleaginous texture on palpation. The two major histological subtypes of SCS are the monophasic and biphasic subtypes $[7,8]$.

Histopathologically, both subgroups have spindle cells proliferating and branching, dilated, thin-walled blood vessels (hemangiopericytomatous pattern) within a heterogeneous collagenous stroma $[1,7]$. A histological subtype, however, is not known to influence survival in HNSS patients. Other features observed in SCS include tumor necrosis, cystic modifications, and calcification. SS are CK, EMA, vimentin and pankeratin (CK AE1/AE3) positive [7, 10]. Molecular testing via fluorescent in situ hybridization
(FISH) and RT-PCR can easily detect the $t(X ; 18)$ (p11.2;q11.2) translocation which is typical in SS (99\%) [7]. Possible combinations of fusion genes are $S Y T-S S X 1$, $S Y T-S S X 2, S Y T-S S X 4$, which can be used to confirm the diagnosis.

\section{ㅁ Conclusions}

To ensure adequate and patient-centered care for HNSS cases, a multidisciplinary team including a head and neck surgeon, a radiation oncologist and a medical oncologist is required. Due to the challenging management and rarity of this malignancy, reporting such cases may lead to its better understanding.

\section{Conflict of interests}

The authors declare that they have no conflict of interests.

\section{References}

[1] Gopalakrishnan V, Amini B, Wagner MJ, Nowell EN, Lazar AJ, Lin PP, Benjamin RS, Araujo DM. Synovial sarcoma of the head and neck: a single institution review. Sarcoma, 2017, 2017:2016752. https://doi.org/10.1155/2017/2016752 PMID: 28655993 PMCID: PMC5474548

[2] Doubi A, Doubi M, Alzaher N, Tulbah A. Synovial sarcoma of the hard palate: the third case in the medical literature. Hematol Oncol Stem Cell Ther, 2019, 12(1):60-63. https:// doi.org/10.1016/j.hemonc.2016.12.005 PMID: 28183682

[3] Lee N, Shin E. Treatment outcomes for patients with synovial sarcoma of the head and neck. Expert Rev Anticancer Ther, 2008, 8(3):371-373. https://doi.org/10.1586/14737140.8.3.371 PMID: 18366285

[4] Shein G, Sandhu G, Potter A, Loo C, Jacobson I, Anazodo A. Laryngeal synovial sarcoma: a systematic review of the last 40 years of reported cases. Ear Nose Throat J, 2021, 100(2): NP93-NP104. https://doi.org/10.1177/0145561319850697 PMID: 31309846

[5] Jang KS, Min KW, Jang SH, Paik SS, Tae K, Jang SJ, Park MH. Primary synovial sarcoma of the thyroid gland. J Korean Med Sci, 2007, 22(Suppl):S154-S158. https://doi.org/10.3346/jkms. 2007.22.S.S154 PMID: 17923744 PMCID: PMC2694401

[6] Harb WJ, Luna MA, Patel SR, Ballo MT, Roberts DB, Sturgis EM. Survival in patients with synovial sarcoma of the head and neck: association with tumor location, size, and extension. Head Neck, 2007, 29(8):731-740. https://doi.org/10.1002/hed. 20564 PMID: 17274049

[7] Jayachandra S, Chin RY, Walshe P. Synovial cell sarcoma of the larynx. Hematol Oncol Clin North Am, 2012, 26(6): 1209-1219. https://doi.org/10.1016/j.hoc.2012.09.001 PMID: 23116577

[8] Kartha SS, Bumpous JM. Synovial cell sarcoma: diagnosis, treatment, and outcomes. Laryngoscope, 2002, 112(11):19791982. https://doi.org/10.1097/00005537-200211000-00013 PMID: 12439166

[9] Ouansafi I, Klein M, Sugrue C, Morgenstern N, Frank D, Wasserman P. Monophasic parapharyngeal synovial sarcoma diagnosed by cytology, immunocytochemistry, and molecular pathology: case report and review of the literature. Diagn Cytopathol, 2010, 38(11):822-827. https://doi.org/10.1002/dc. 21328 PMID: 20973043

[10] Salcedo-Hernández RA, Lino-Silva LS, Luna-Ortiz K. Synovial sarcomas of the head and neck: comparative analysis with synovial sarcoma of the extremities. Auris Nasus Larynx, 2013, 40(5):476-480. https://doi.org/10.1016/j.anl.2012.11.015 PMID: 23260343

[11] Jain A, Saxena A, Meher R, Khurana N. Synovial sarcoma of the ethmoid sinus. Eur Ann Otorhinolaryngol Head Neck Dis, 2018, 135(6):453-455. https://doi.org/10.1016/j.anorl.2017.10. 007 PMID: 30352776

[12] Moţ IC, Poenaru M, Mogoantă CA, Istrate-Ofiţeru AM, Oprişcan IC, Sarău CA, Mănescu MD, Enăchescu V, Dogaru CA, Popescu C, Morar R, Balica NC, Horhat ID. Head and neck metachronous 
tumors - clinical, histopathological and immunohistochemical study. Rom J Morphol Embryol, 2019, 60(4):1199-1206. PMID: 32239095

[13] lovănescu G, Bîrsăşteanu F, Borugă VM, Apostol A Ştefănescu EH, Budu VA, Baderca F, Trifu SC, Mogoantă CA, Bonţe DC, Ivan MV. Clinical, ultrasound and histopathological correlation of clinically N0 neck nodes in patients with cancers of the pharynx and larynx. Rom J Morphol Embryol, 2020, 61(2):433-439. https://doi.org/10.47162/RJME.61.2.12 PMID: 33544794 PMCID: PMC7864314

[14] Vrînceanu D, Dumitru M, Ştefan AA, Mogoantă CA, Sajin M. Giant pleomorphic sarcoma of the tongue base - a cured clinical case report and literature review. Rom J Morphol Embryol,
2020, 61(4):1323-1327. https://doi.org/10.47162/RJME.61.4. 34 PMID: 34171081 PMCID: PMC8343483

[15] Stanbouly D, Litman E, Lee KC, Philipone E. Synovial sarcoma of the head \& neck: a review of reported cases in the literature. J Stomatol Oral Maxillofac Surg, 2021, 122(5):505-510. https:// doi.org/10.1016/j.jormas.2020.12.001 PMID: 33301946

[16] Salinas R, Hussey DH, Fletcher GH, Lindberg RD, Martin RG, Peters LJ, Sinkovics JG. Experience with neutron therapy for locally advanced sarcomas. Int J Radiat Oncol Biol Phys, 1980, 6(3):267-272. https://doi.org/10.1016/0360-3016(80)90132-7 PMID: 6248496

\section{Corresponding authors}

Konstantinos Sapalidis, Associate Professor of Surgery, MD, PhD, $3^{\text {rd }}$ Department of Surgery, AHEPA University Hospital, Medical School, Aristotle University of Thessaloniki, 1 Kiriakidi Street, 54621 Thessaloniki, Greece; Mobile +306944706828, e-mail: sapalidiskonstantinos@gmail.com

Daniel-Cristian Pîrvu, Assistant, MD, PhD, Department of Internal Medicine, Faculty of Medicine, University of Medicine and Pharmacy of Craiova, 2 Petru Rareş Street, 200349 Craiova, Romania; Phone +40748-188 010, e-mail: daniel.pirvu@umfcv.ro

Received: May 23, 2021

Accepted: January 7, 2022 